\title{
Retinal Fibers Alter Tectal Positional Markers during the Expansion of the Half Retinal Projection in Goldfish
}

\author{
JOHN T. SCHMIDT \\ Biophysics Research Division and Division of Biological Sciences, University of Michigan, \\ Ann Arbor, Michigan 48109, U.S.A.
}

\begin{abstract}
Although widely accepted, the theory, that neurones carry immutable cytochemical markers which specify their synaptic connections, is not consistent with plastic reorganizations. Half retinal fish were therefore tested for changed markers following expansion. Optic nerve crush at the time of the half retinal ablation resulted in regeneration of a normal, restricted projection; but nerve crush following expansion (many months later) resulted in reestablishment of the expanded projection, assessed both by electrophysiological mapping and by radioautography. Since this implied changed markers, the half retina and tectum were tested independently using the ipsilateral tectum and eye as controls. In normal fish, removal of one tectum and deflection of the corresponding optic tract toward the remaining tectum resulted in regeneration of a positionally normal but ipsilateral map. In experimental fish, after the half retina had expanded its projection to the contralateral tectum, its optic tract was deflected to the control tectum. After 40 days it had regenerated a normal, restricted map indicating that the retinal markers had not changed. Such restricted projections did not expand in the presence of the normal projection even after a year or more. Similarly, the optic tract from the normal eye was deflected to cause innervation of the tectum containing the expanded half retinal projection. After 40 days, the projection regenerated from the normal eye was similar to the expanded half retinal projection. Areas of the normal retina corresponding to the missing areas of the half retina were not represented. Tectal markers had been altered by the half retinal fibers. In a final group, tecta were denervated and tested at various intervals by innervation from ipsilateral half retinal eyes. After five months of denervation, the regenerating fibers were no longer restricted to the rostral tectum but formed an expanded projection initially. Apparently tectal markers are induced by the retinal fibers, changed during expansion, and disappear during long-term denervation.
\end{abstract}

Following crush of the optic nerve in am. phibians and teleosts, the retinal ganglion cells regenerate their axons to reestablish orderly connections in the brain (Matthey, '25; Sperry, '44, '45, '48). The optic tectum, the major target area, receives a retinotopic projection and its regeneration is a highly selective process (Attardi and Sperry, '63; Jacobson and Gaze, '65). After removing portions of the retina and crushing the optic nerve in goldfish, Attardi and Sperry found histologically that the regenerating fibers bypassed empty areas to arborize only in appropriate areas. To explain this selectivity, Sperry ('63) postulated that, during develop- ment, the cells of both the retina and tectum had acquired individual "cytochemical tags" and that ingrowing axons linked only with those neurones carrying similar tags via "specific chemical affinities."

Later experiments involving ablations to portions of either the retina or tectum of goldfish showed that the connections, as assessed by the electrophysiological mapping technique, were capable of rearrangements so that whatever portion of retina remained projected topographically to fill the available tectal area (Systems Matching: Gaze and Keating, 72). Half of the tectum could receive fibers from the entire retina (Gaze and Sharma, '70; 
Yoon, '71; Schmidt et al., '74), and similarly half of a retina could project over the entire tectum (Schmidt et al., '77; Yoon, '72). Optic fibers first regenerated to occupy the appropriate sites, but after several months moved to new locations. (Gaze and Sharma, '70; Sharma, '72; Schmidt et al., '77).

These findings of altered projections to the tectum forced a change in Sperry's formula. tion of neuronal specificity. The postulated neuronal tags or markers must somehow change to allow the formation of new projections. Meyer and Sperry ('73) postulated that the rapidly growing adult goldfish retains the embryonic property of regulation, by which a fragment of a developing organ can reorganize to take on the properties of the whole organ. In the case of the expansion of a half retinal projection, half of the adult retina might assume a full set of retinal markers to match those of a complete tectum. Assuming that retinal (and tectal) positional information is encoded along two orthogonal axes (Székely, '54; Sperry, '63; Jacobson, '68), a model of markers sim. ilar to Cartesian coordinates will suffice to illustrate, with values running (arbitrarily) from 1 to 10 along each axis. Removing the nasal half retina would halve the range in that dimension ( 1.5 for instance), but regulation would restore the full range (1-10) over the remaining half retina.

Alternatively, the half retinal fibers might induce the tectum to assume only half of its normal set of markers. In this case, the tectum would discard markers 6 through 10 , and distribute the remaining markers (1-5) over its length, to match those of the half retina. Yoon ('71) has termed this type of process "synaptic respecification." Thus either set of markers, retinal or tectal, could change during the expansion, and simply mapping the projection between the half retina and its tectum does not distinguish between these (or other) possibilities. A true operational assay for markers requires a normal set against which to test either suspect set. For instance, the half retina, which has expanded its projection over the contralateral tectum, can be tested by induc. ing it to innervate a second normal tectum. The markers of the half retina can then be inferred from the projection mapped soon after regeneration, before any further reorganization can take place. I have used the tectum ipsilateral to the half retinal eye as the normal tissue; ipsilateral projections were induced using a variation of the method of Sharma ('73). In an analogous experiment, the suspect tectal markers were assessed by mapping the projection which a normal eye formed upon the experimental tectum.

\section{METHODS \\ Surgery}

All surgery was carried out in air, following anaethetization of the fish in a $0.1 \%$ solution of tricaine methanesulfonate. Several procedures were used: intraorbital crush of the optic nerve (Schmidt et al., '77), removal of one tectal lobe and deflection of the stump of the corresponding optic tract (Easter and Schmidt, '77), and enucleation of one eye. According to which of these was done, and when, the animals were assigned to one of five experimental groups, described in the $\mathrm{RE}$ SULTS. A total of 85 goldfish are included in this report, 68 of which were drawn from the group in the preceding paper (Schmidt et al., 77).

\section{Electrophysiology}

Electrophysiological recordings and computations of the magnification factors (MF's) were carried out using the methods described previously (Schmidt et al., '77). For mapping the projections of both eyes to one tectum, the hemisphere was mounted so that it could be rotated left or right to a position centered on either eye while recording from each penetration in the tectum.

Single units were sometimes recorded, and classified as retinal fiber terminals or tectal cells on the basis of the following criteria (O'Benar, '71). Fiber terminals had small circular receptive fields $\left(9-13^{\circ}\right.$ diameter) and always responded to the repeated entry of light into these fields. These comprised the vast majority of units recorded and all of those whose receptive fields are shown in the maps. Units which habituated to repeated presentations of a light stimulus were classified as tectal cells, as were units which did not habitu. ate, but which had extremely large completely inhibitory fields. These three types comprised all units encountered.

\section{Radioautography}

When possible, the fish were revived after the final recording and injected intraocularly with $\mathrm{L}-(2,3)-{ }^{3} \mathrm{H}$-proline for radioautographic tracing of the projection using the technique previously described (Schmidt et al., '77). 


\section{RESULTS}

The results from five groups of fish are presented here. Each group was designed to test a different question, and the rationale is given with each.

\section{Group I: Test for persistence of normal retinal and tectal markers following expansion}

Six fish, previously established to have ex panded half retinal projections (Schmidt et al., '77), had the optic nerve crushed intraorbitally. They were allowed to regenerate a new projection, which was then determined electrophysiologically and radioautographically. Regeneration of a projection restricted to the rostral half tectum would indicate that the original, normal set of retino-tectal markers was still present after the expansion. However, immediate regeneration of a projection extending over the whole length of the tectum would indicate that the markers had changed. This initial test was, therefore, for a change in either set of the markers presumed to be matched in the selective regeneration process (Sperry, '63).

Four of the six fish died before they could be remapped, but in the other two the expanded projection was found to be reinstated on the tectum after 46 and 50 days. Figure 1 shows the expanded projection regenerated in HR-55 and mapped 46 days after the crush. The rostro-caudal magnification factor (RCMF) of the regenerated map was $49.0 \mu \mathrm{m} /{ }^{\circ}$, over twice the normal value, but the medio-lateral magnification factor (MLMF) was within the normal range, as found for expansions previously (Schmidt et al., '77). The means and standard errors of the magnification factors (MF's) are listed in table 1 . In addition to the two fish above, similar results were also obtained in two fish included in Group IV. In all, four fish whose expanded projections were interrupted by nerve crush regenerated expanded projections; none regenerated the normal projection.

One of these (HR-55, whose map is given in fig. 1) was successfully injected for radioautography following the final recording. A dark field radioautograph of the regenerated projection is shown in figure 11A. The silver grains extended over the length of the tectum.

As a control, radioautographs were made of the projections regenerated from newly created half retinae. Two fish were injected 41 days after half retinal ablation and interruption of

TABLE 1

Magnification factors computed for each group of fish

\begin{tabular}{|c|c|c|c|c|c|}
\hline & Projection & Notes & $\mathrm{N}$ & $\begin{array}{l}\text { RCMF } \\
(\mathrm{SEM})\end{array}$ & $\begin{array}{l}\text { MLMF } \\
\text { (SEM) }\end{array}$ \\
\hline Group I & $\begin{array}{l}\text { HR eye-expt'l tectum } \\
\text { HR eye-expt'l tectum }\end{array}$ & $\begin{array}{l}\text { Expanded; before crush } \\
\text { Regenerated ( } 46: 72 \text { days) }\end{array}$ & $\begin{array}{l}2 \\
4\end{array}$ & $\begin{array}{c}\mu \mathrm{m} /{ }^{\circ} \\
33.7(8.7) \\
44.2(5.1)\end{array}$ & $\begin{array}{l}\mu \mathrm{m} /{ }^{\circ} \\
11.9(-) \\
21.1(1.2)\end{array}$ \\
\hline Group II & $\begin{array}{l}\text { Ipsilateral projections } \\
\text { Contralateral projections }\end{array}$ & (41-114 days) & $\begin{array}{l}5 \\
2\end{array}$ & $\begin{array}{l}17.6(1.4) \\
18.6(0.5)\end{array}$ & $\begin{array}{l}17.8(1.8) \\
18.1(2.9)\end{array}$ \\
\hline Group III-1 & $\begin{array}{l}\text { HR eye-expt'l tectum } \\
\text { HR eye-control tectum } \\
\text { Control eye-control tectum }\end{array}$ & $\begin{array}{l}\text { Expanded; before deflection } \\
\text { Normal; regenerated (41-67 days) }\end{array}$ & $\begin{array}{l}4 \\
5 \\
5\end{array}$ & $\begin{array}{l}43.5(6.8) \\
20.4(1.1) \\
19.2(0.6)\end{array}$ & $\begin{array}{l}21.5(2.0) \\
20.0(1.7) \\
21.1(1.8)\end{array}$ \\
\hline Group III-2 & $\begin{array}{c}\text { HR eyes Ipsilateral } \\
\text { Contralateral } \\
\text { Combined } \\
\text { Intact eyes (Combined) }\end{array}$ & $\begin{array}{l}\text { Long term projections } \\
\text { (188-455 days) }\end{array}$ & $\begin{array}{l}3 \\
3 \\
6 \\
6\end{array}$ & $\begin{array}{l}21.3(3.1) \\
18.1(0.8) \\
19.7(1.6) \\
19.1(0.6)\end{array}$ & $\begin{array}{l}23.5(4.0) \\
22.6(1.1)\end{array}$ \\
\hline Group IV & $\begin{array}{l}\text { HR eye-expt'l tectum } \\
\text { HR eye-expt'l tectum } \\
\text { Control eye-expt'l tectum }\end{array}$ & $\begin{array}{l}\text { Expanded; before deflection } \\
\text { Expanded } \\
\text { Expanded; regenerated }\end{array}$ & $\begin{array}{l}3 \\
5 \\
5\end{array}$ & $\begin{array}{l}37.7(9.8) \\
36.6(5.8) \\
32.3(3.8)\end{array}$ & $\begin{array}{l}17.1(1.7) \\
19.6(0.6) \\
18.9(0.6)\end{array}$ \\
\hline Group V-1 & $\begin{array}{l}\text { HR eye-expt'l tectum } \\
\text { Control eye-expt'l tectum } \\
\text { Control eye-expt'l tectum }\end{array}$ & $\begin{array}{l}\text { Expanded; before deflection } \\
\text { Unprimed; expanded; regenerated } \\
\text { Primed; normal; regenerated }\end{array}$ & $\begin{array}{l}3 \\
7 \\
7\end{array}$ & $\begin{array}{l}32.1(2.3) \\
31.2(1.8) \\
19.7(0.8)\end{array}$ & $\begin{array}{l}16.8(0.2) \\
21.0(1.6) \\
23.5(1.7)\end{array}$ \\
\hline Group V.2 & $\begin{array}{l}\text { HR eye-ipsilateral tectum } \\
\text { HR eye-ipsilateral tectum }\end{array}$ & $\begin{array}{l}\text { Denervated } 0-60 \text { days } \\
\text { Denervated } 159-190 \text { days } \\
\quad \text { (regenerated } 36-45 \text { days) }\end{array}$ & $\begin{array}{l}3 \\
3\end{array}$ & $\begin{array}{l}14.8(2.4) \\
40.8(5.6)\end{array}$ & $\begin{array}{l}23.1(1.6) \\
20.7(0.2)\end{array}$ \\
\hline Normals & $\begin{array}{l}\text { Entire tectum } \\
\text { Rostral tectum only }\end{array}$ & & 8 & $\begin{array}{l}18.6(0.8) \\
15.5(1.2)\end{array}$ & $21.1(1.0)$ \\
\hline
\end{tabular}


RIGHT VISUAL FIELD

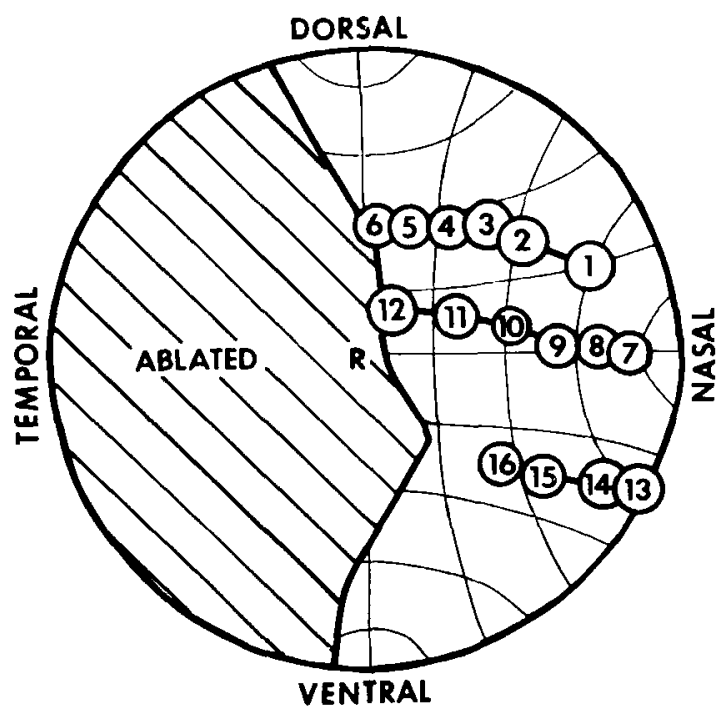

LEFT TECTUM

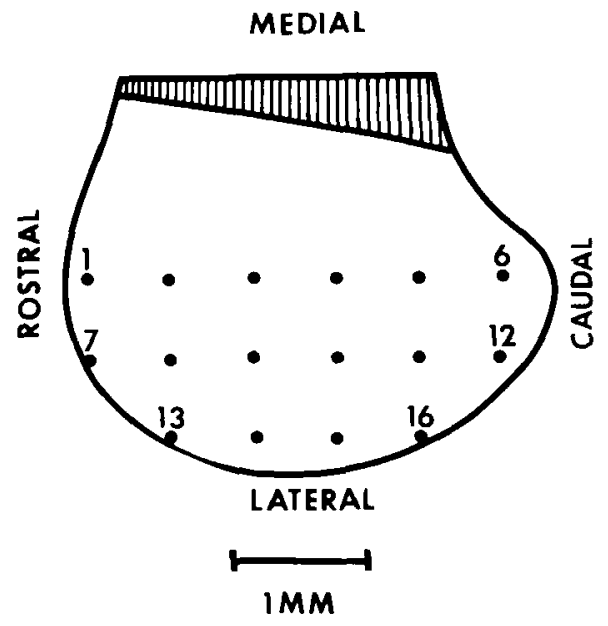

Fig. 1 Expanded half retinal projection of HR-55, mapped 46 days after crush of the optic nerve. The projection was expanded at the time of the crush, 234 days after the ablation of the nasal retina (corresponding to the striped area in the temporal field). Circles give the approximate size of the receptive fields found at numbered tectal penetrations. " $R$ " marks the optic axis of the eye determined by the corneal reflection technique. The hemisphere is marked at $20^{\circ}$ intervals.

the optic fibers of the same eye. Both gave the same result; the silver grains were restricted to the rostral half of the tectum as seen in figure 11B. The previous paper (Schmidt et al., '77) described the corresponding electrophysiological control. The regenerated projection, mapped 36 days after nerve crush and half retinal ablation was also restricted to the rostral half tectum.

\section{Conclusion}

The markers within either the half retina or its contralateral tectum were altered during the expansion of the half retinal projection.

\section{Group II: Test for equivalence of ipsilateral and contralateral tectal markers}

If the normal retina and tectum are to be used as standard sets of markers, it must first be shown that a normal retina can project retinotopically to the ipsilateral tectum. Seventeen normal fish had one tectal lobe removed and the corresponding optic tract deflected to the opposite side. The other optic tract was left intact.

Seven animals died before any results were obtained. Five others were mapped electrophysiologically at 41 to 114 days postoperatively. The maps were orderly; both eyes pro- jected to the same tectum, and corresponding sites in the two visual fields mapped to the same tectal loci (Sharma, '73; Schmidt and Easter, '77). The MF's of the ipsilateral and contralateral projections were very nearly the same, both rostro-caudally and medio-laterally, and all were well within the normal range (table 1, group II). Eight animals (including three of those mapped) were assessed radioautographically following injection of ${ }^{3} \mathrm{H}$-proline into the experimental eye at 40 to 140 days postoperatively. All showed the normal distribution of grains within the ipsilateral tectum (Easter et al., '77).

\section{Conclusion}

The retina, when forced to innervate the ipsilateral tectum, does so retinotopically. Therefore, the formation of ipsilateral projec-

Fig. 2 Procedure and results of the test for retinal regulation.

A Expanded projection of the half retina to the contralateral tectum, mapped 236 days after retinal abla. tion.

B Schematic diagram showing the ensuing surgical removal of the tectum with the expanded projection and deflection of the fibers toward the ipsilateral control tectum.

C Normal projection regenerated from this half retinal eye to the control tectum, mapped 42 days later in the same fish. 
A RIGHT VISUAL FIELD

LEFT TECTUM
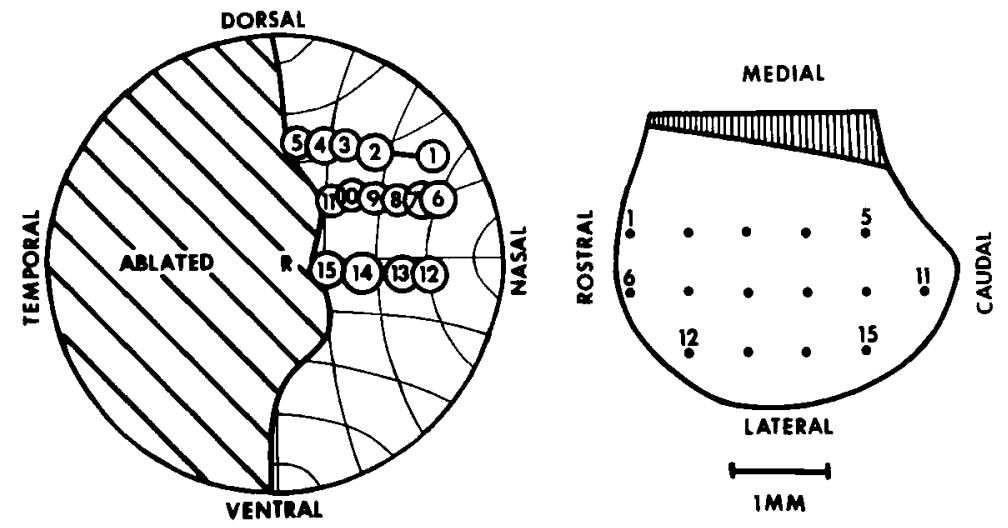

B

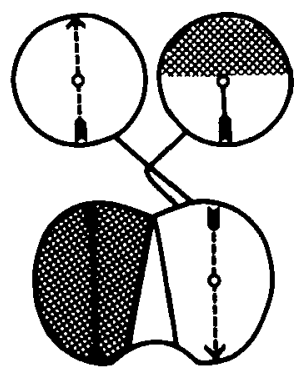

C
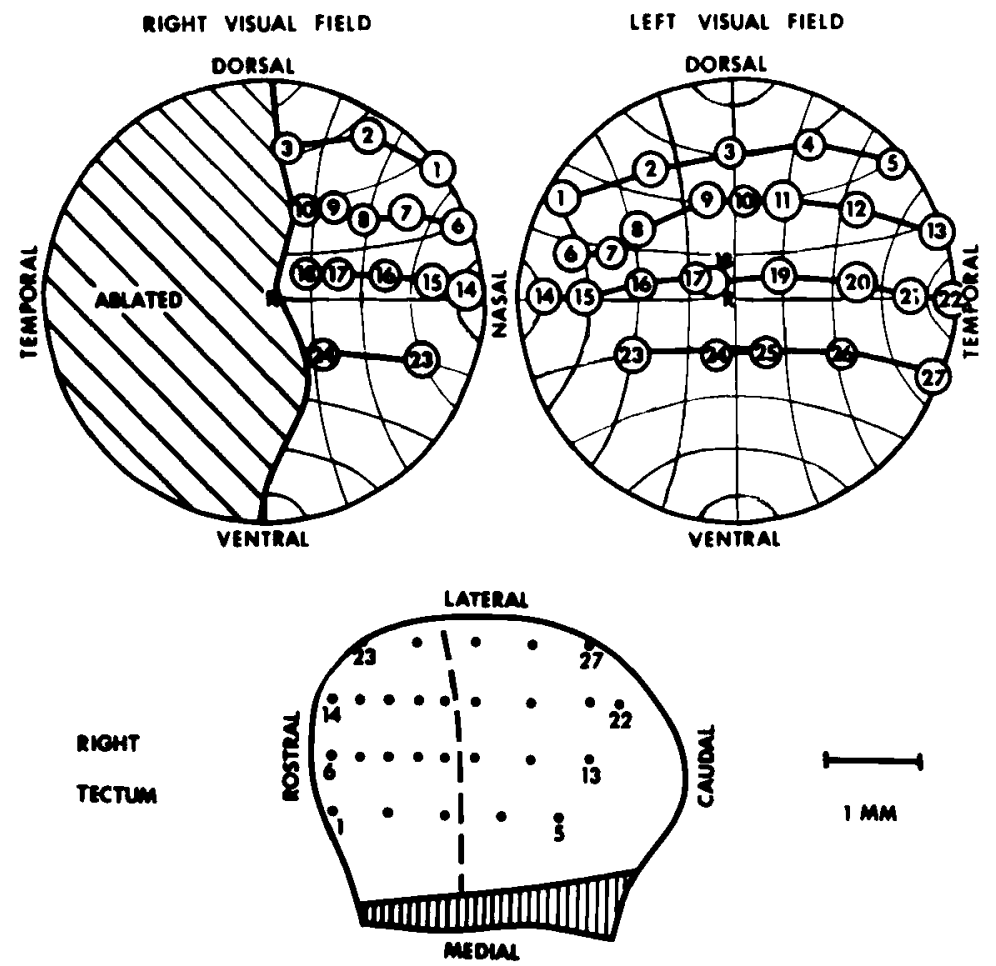

Figure 2 
tions provides a valuable control system within each half retinal fish.

\section{Group III: Tests for changes in retinal markers}

Fourteen half retinal fish (Group III-1), pre. viously shown to have expanded projections (Schmidt et al., '77), were used. Each had the contralateral tectum (containing the expanded projection) removed, and the optic tract from the half retinal eye deflected ipsilaterally to induce innervation of the remaining control tectum (fig. 2B). If the markers of the half retina had changed, it should form an expanded projection on the control tectum as well. If the half retina was unchanged, a normal projection, restricted to the rostral half tectum, should result.

Five fish survived to the second recording 41 to 67 days later. In all cases, the half retina projected only to the rostral half of the control tectum, as shown in figure 2. Part A shows the initial expanded projection to the contralat. eral tectum wherein each series of penetrations across the tectum corresponds to a series of receptive fields across the half retina. Part $B$ schematizes the surgery which was done immediately after obtaining the map of Part A. Then, 42 days later, the ipsilateral retino-tectal map was determined and is shown in Part C. Penetrations rostral to the dashed line on the tectum recorded retinal units from both the right and left eyes. These units had receptive fields at normal positions in both visual fields. Caudal to this line, the only units recorded were from the appropriate temporal region of the left, normal visual field. In each case, an exhaustive search of the caudal tectum to depths of $300 \mu \mathrm{m}$ or more failed to find any activity from the half retina.

The MF's of the half retinal projections to the ipsilateral control tecta were computed and compared with those from the earlier expanded projections. The RCMF's of the expanded maps were consistently about twice the normal value, but those of projections subsequently regenerated to the control tecta were consistently within the normal range. The means and standard errors of these MF's are given in table 1 (Group III-1). The MLMF was normal for both types of half retinal projection.

Two of the fish, HR-32 and HR-58 (whose maps are shown in fig 2 ), were successfully revived and injected for radioautography. Dark field micrographs of their projections are shown in figures $11 \mathrm{C}$ and $11 \mathrm{D}$ respectively. HR-32 showed moderate grain density within the retinal terminal bands rostrally, and no grains caudally, in agreement with the electrophysiological map. In HR-58, which was much more heavily labelled, the grain density was very much higher rostrally than caudally, but there were some grains within the caudal half. The very much lower level of label there and the absence of electrical signals suggest that these grains originated from a relatively few optic fibers which had strayed and failed to arborize. Alternatively, they may have entered the ventrolateral branch of the optic tract, and grown from the ventrocaudal margin over the dorsocaudal tectum to terminate rostrally.

I also determined whether half retinal projections within dually innervated tecta (such as fig. 2 C) could eventually expand, as a second, less direct test for changes in the retinal markers. Twelve additional fish (Group III-2) were operated as shown in figure $2 \mathrm{~B}$, except that each fish had the optic tract deflected at the same time that the half retina was removed. The half retinal eye was ipsilateral or contralateral to the remaining tectum in six cases each. If the half retinal expansion depended on a change in retinal markers, then one would expect the two projections to be independent of one another. Specifically the half retina should first project to the rostral half of the tectum, and then after a delay of about 150 days, expand to cover the tectum (Schmidt et al., '77), while the intact retina should continue to project normally.

Six of these fish (3 of each type) were mapped from 188 to 455 days postoperatively; three were radioautographed (including one of those mapped); and four died. None of the six maps showed the expansion of the half retinal projection even after 455 days, nearly three times the usual period of time required for such expansion (Schmidt et al., '77). No differences were noted between those cases where the half retina was ipsilateral rather than contralateral to the remaining tectum. There were, however, slight differences between the earlier and later maps. The four maps recorded between 188 and 286 days postoperatively were quite orderly and similar to that shown in figure $2 \mathrm{C}$. The two fish mapped later at 454 to $\mathbf{4 5 5}$ days had less orderly projections; one of these is shown in figure 3 . At several penetrations within the appropriate rostral half tectum (penetrations 7, 19, 20 and 

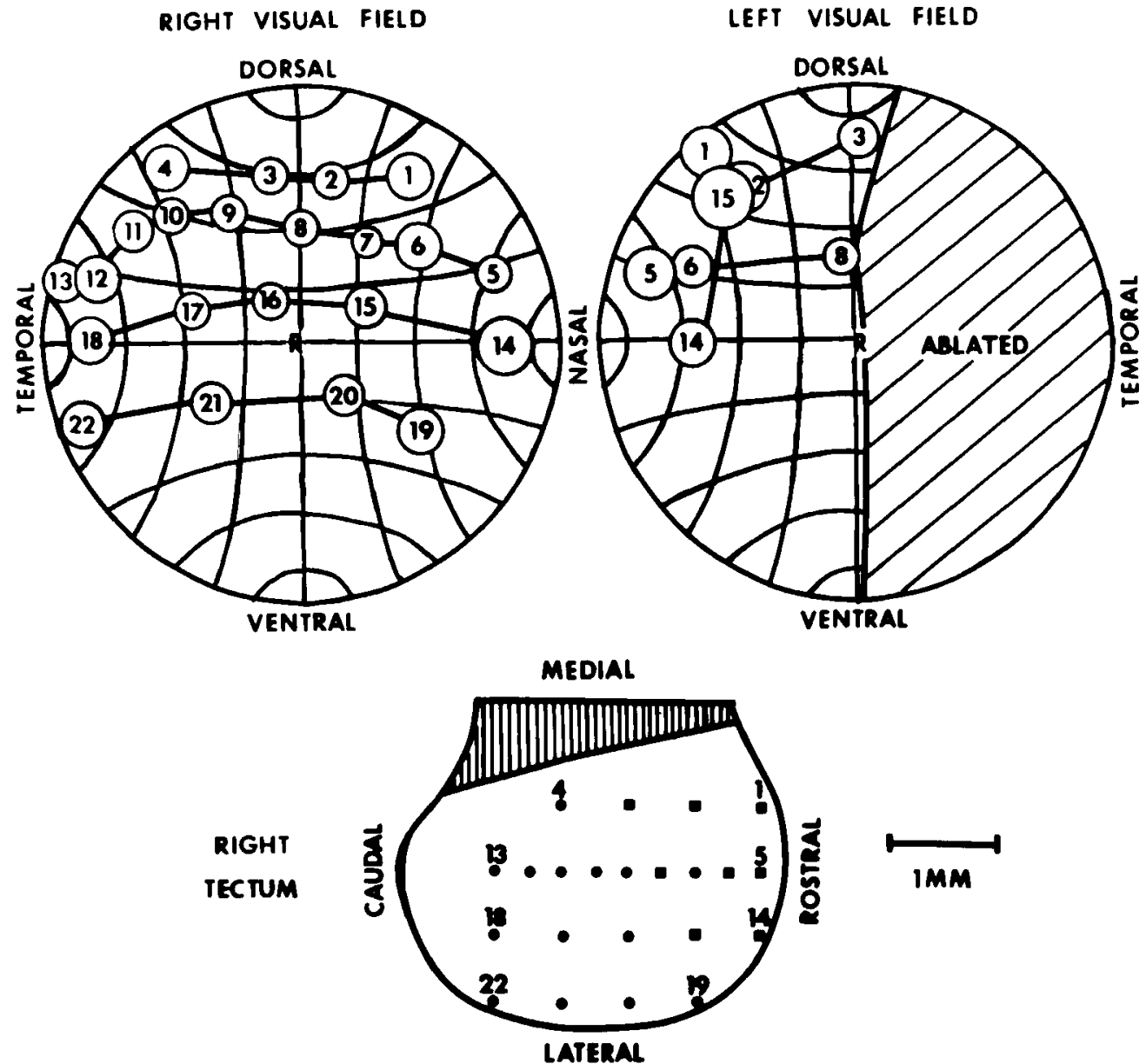

Fig. 3 Long term projections of intact and half retinal eyes to one tectum, mapped 455 days postoperatively. Squares indicate penetrations with units recorded from the half retinal eye as well as from the intact eye; cir. cles, those with units only from the intact eye.

perhaps also 16), no units could be recorded from the half retina; and at other penetrations the receptive fields were occasionally at inappropriate positions. This suggestion of partitioning between the projections of the two eyes was confirmed in the radioautographs of three fish. Figure 12B shows the patchiness which was present in all cases within the rostral tectum, following injections of the intact ipsilateral eye. The presence of the unlabelled patches rostrally correlates with the restricted maps found electrophysiologically. Unlike the patches noted by Jacobson and Levine ('75), these were prominent only after long postoperative intervals. They do not appear in figures $11 \mathrm{C}$ and $11 \mathrm{D}$, and are only slightly apparent in figure $12 \mathrm{~A}$.
The average MF's computed for these fish are also listed in table 1 (Group III-2). Both the RCMF's and MLMF's from both the intact and half retinal eyes were within the normal range in all cases.

\section{Conclusion}

The markers of the half retina do not change during the expansion of the projection. The expanded projections regenerated in Group I therefore suggest a change in tectal markers during expansion.

\section{Group IV: Tests for changes in tectal markers}

Eight half retinal fish with expanded projections were used ( 3 with expanded maps at 
166 to 179 days, and 5 others which were not mapped but presumed to have expanded projections after longer postoperative intervals). Each fish had the normal tectum removed, and the optic tract from the normal eye deflected ipsilaterally to induce innervation of the tectum containing the expanded projec. tion (fig. 4B). Formation of normal projections from the normal eye would indicate normal tectal markers. If the tectal markers had changed, one would expect an expanded projection to form. In four fish (Group IV-1), the half retinal projection was left intact, while in the other four (Group IV-2), the optic nerve was crushed intraorbitally at the time that the control optic tract was deflected. Thus, in the first group, the control eye's projection would form in the presence of an intact expanded projection, while in the second, the projections from the control and half retinal eyes would form simultaneously.

Five fish ( 3 from Group IV -1 and 2 from Group IV-2) survived to the second mapping 38 to 72 days later, and all showed systematically abnormal projections from the control eyes. Figure 4 illustrates the results of one fish from Group IV-1. Figure 4A shows the expanded projection of the half retinal eye mapped before the innervation by the control eye. Figure $4 \mathrm{C}$ shows both it and the projection formed by the innervation from the left, control eye mapped 38 days later. The part of the control visual field corresponding to the remaining portion of the half retinal visual field projected in expanded fashion over the tectum. The receptive fields at each tectal penetration were at positions nearly mirror symmetrically located across the midline. The dashed line in the control visual field marks off the area corresponding to the ablated region of the half retinal field. In the half retinal eye, this region was imaged onto areas from which the retina had been removed; but in the control eye, this region was imaged onto intact retina. This large area of normal retina was not represented on the tectal surface at any of the points mapped.

The two survivors of Group IV-2, in which both sets of optic fibers regenerated into the tectum together, produced similar results. The final map of one of these, HR-34, is shown in figure 5 . The half retina regenerated an expanded projection (compare with Group I, fig. 1). The corresponding half of the control retina also formed an expanded projection, but the non-corresponding half was not represented on the tectum. This result indicated that in Group IV-1, the fibers of the control eye were not merely following intact corresponding fibers from the half retinal eye, since here both grew in together with the same result.

Since both groups have the same result, their MF's are listed together in table 1. The RCMF's of the expanded projections regenerated from the control eyes were nearly twice the normal value, as were the RCMF's of the half retinal eyes at both mappings. MLMF's were once again normal.

The projections from the control eyes of two of these fish were traced radioautograph. ically. A dark field micrograph of the projection of one (HR-36) is shown in figure 12A. The density of silver grains was heavy (in both cases) both rostrally and caudally, and there was no obvious increase in either grain density or thickness of the main retinal terminal band caudally where the unrepresented area of retina would normally project. In short, the projections shown in the radioautographs were roughly normal, and there was no indication of where the fibers from the unrepresented areas of the retinae might have gone.

\section{Conclusion}

Tectal markers were changed during the expansion, as evidenced by the formation of abnormal expanded projections from normal eyes. The changeable nature of the tectal markers and their close dependence on the previous innervation both suggested that the tectum does not generate them independently, and they might be expected to disappear during long-term denervation of the tectum.

\section{Group V: Tests for persistence of tectal markers in denervated tecta}

In all the experiments described thus far, the ipsilateral innervation was generated with the contralateral projection in place or only briefly interrupted by optic nerve crush. In the experiments to be described here, tectal markers were tested by ipsilateral projections at various intervals after complete removal of

Fig. 4 Procedure and results of the test for altered tectal markers.

A Expanded half retinal projection of HR-23 mapped 171 days after the retinal ablation.

B Schematic diagram showing the ensuing surgical removal of the control tectum and deflection of the control fibers ipsilaterally.

C Abnormal projection regenerated from the control eye to the experimental tectum, mapped 38 days later in the same fish. 
A RIGHT VISUAL FIELD

LEFT IECTUM
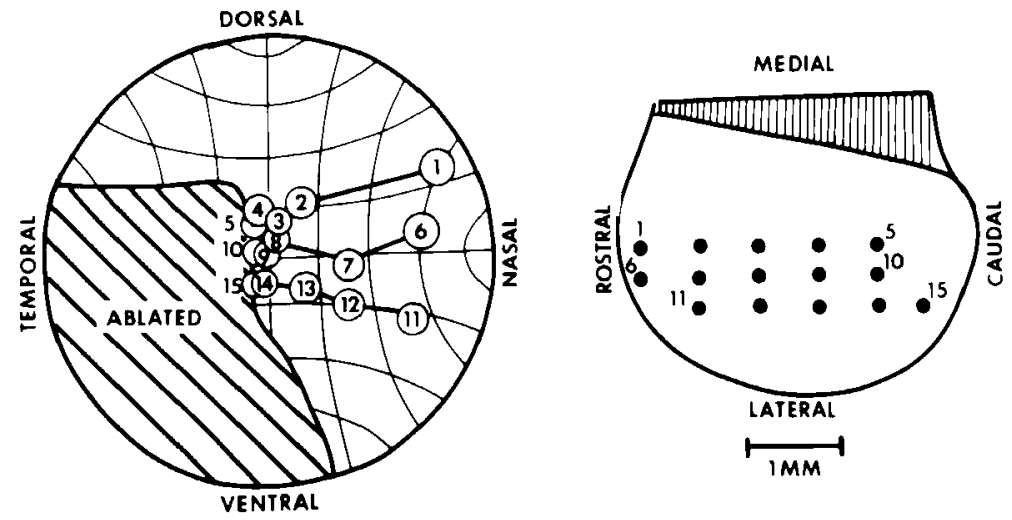

B

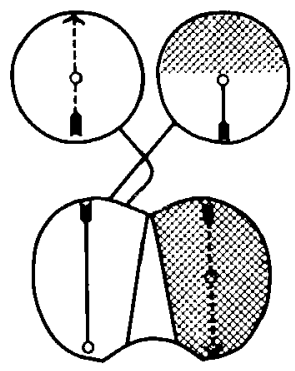

C
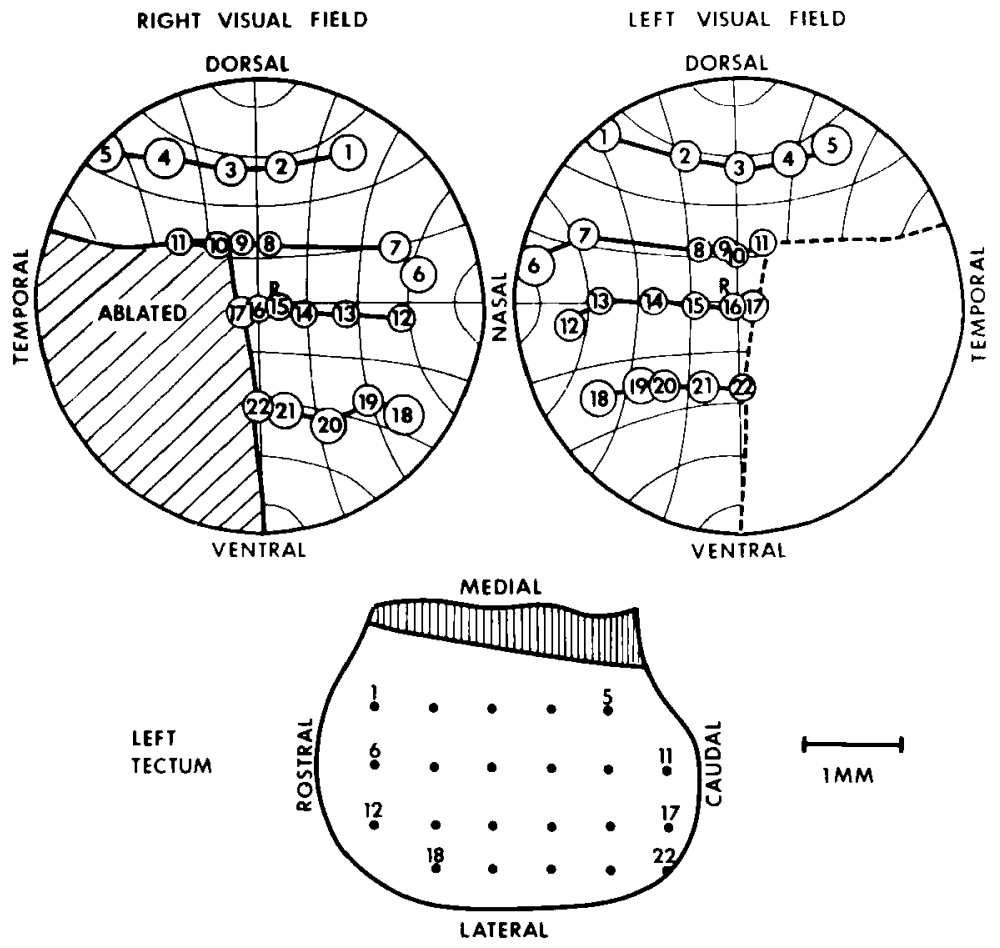

Figure 4 

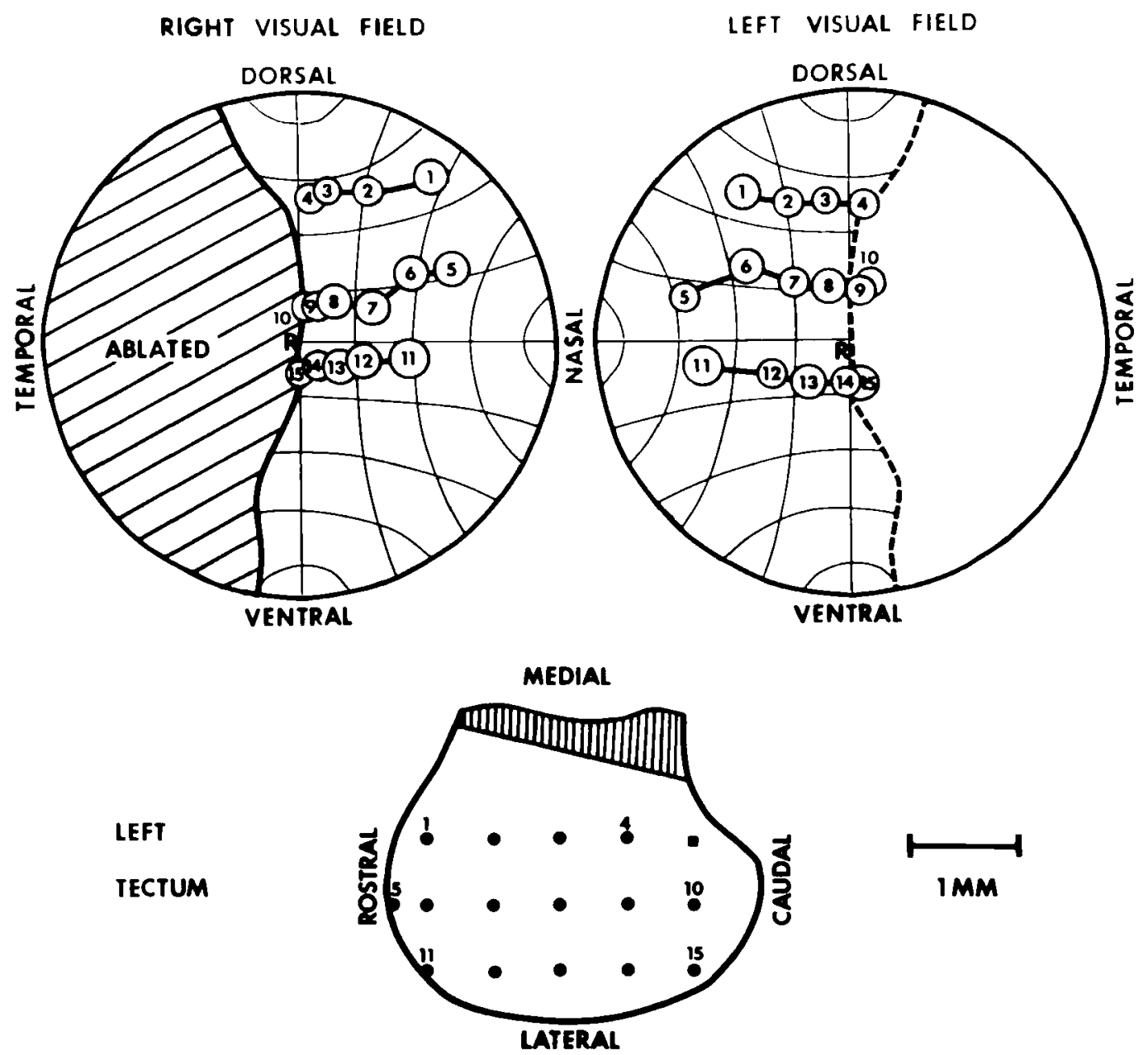

Fig. 5 Projections of half retinal and control eyes regenerated to the experimental tectum, mapped 70 days later. The fibers of the control eye were deflected as in figure $4 \mathrm{~B}$, and those of the half retinal eye were interrupted by crush.

the contralateral eye; that is, after varying periods of denervation of the tectum. Two groups were used; Group V-1 to test the persistence of altered tectal markers, and Group $\mathrm{V}-2$ to test the persistence of normal tectal markers.

The persistence of altered tectal markers (Group V.1) was investigated using nine fish with expanded half retinal projections ( 3 were mapped at 206-259 days postoperatively and 6 others, not mapped, were presumed to be expanded after 211-225 days). The procedure is outlined in figure 6 . After the expansion, the half retinal eye was removed. From 0 to 150 days later, the optic tract of the control eye was deflected to induce innervation of the denervated tectum.

Seven of these fish survived and were recorded. In three cases, the deflection of the optic tract accompanied the removal of the half retinal eye. The control eye (mapped 4243 days later) formed a somewhat different pattern of innervation than that found in Group IV (figs. 4C, 5), but still demonstrated the altered tectal markers. The two projections of $\mathrm{HR}-60$ shown in figures $7 \mathrm{~A}$ and $7 \mathrm{~B}$ are typical. Part A shows the expanded projection of the right half retinal eye, and part $B$ the subsequent projection from the control eye to the same tectum. The control eye formed a 


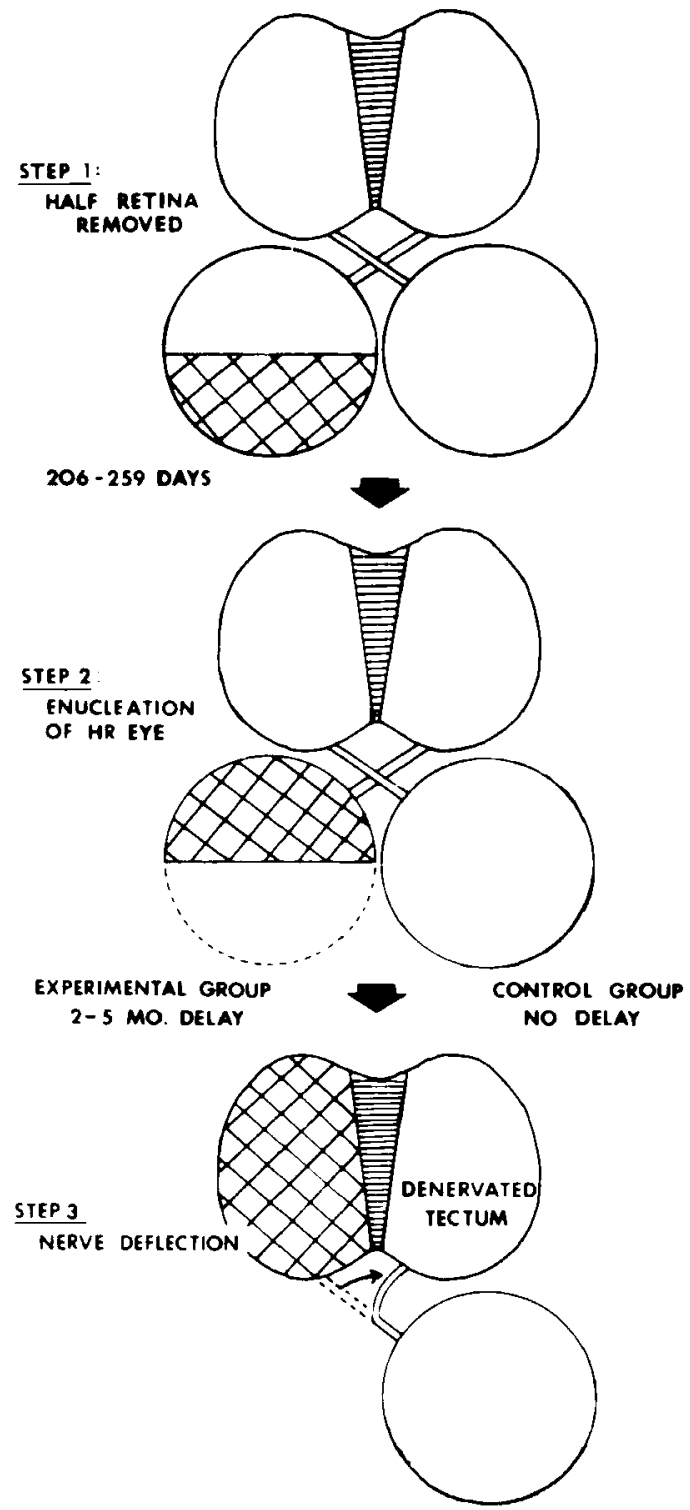

Fig. 6 Schematic diagram of the surgical procedure used in Group V.1.

double projection. That half of the control retina, which corresponded to the previous half retina, projected in expanded fashion over the tectum, as before. In addition there was a roughly normal projection from the entire retina to the tectum. Nearly every penetration yielded two receptive fields systematically separated along the naso-temporal direction in the visual field. The more nasal of each pair, designated by the unprimed numbers was appropriate to an expanded half retinal projection. These are connected by the solid lines, and all of them fell within the area (marked off by the dashed line) which corresponded to the remaining portion of the visual field of the half retinal eye (above), before it was re. moved. The more temporal of each pair of receptive fields, designated by the primed numbers, was appropriate to a normal projection. These were found all across the visual field. The separation between the pairs of receptive fields was greatest for penetrations in the far caudal tectum (where one was found at the midline and the other far temporally), and decreased as penetrations were made more rostrally. This type of ordering would be expected if the two sets of receptive fields represented an expanded half retinal and a normal projec. tion respectively.

MF's were computed for each of the two sets of receptive fields (primed and unprimed), and the means are listed in table 1 (Group V-1). The unprimed fields which formed the expanded projections had RCMF's nearly identical to those of the preceding expanded half retinal projections, while the primed fields comprising the normal projections had roughly normal RCMF's.

In the other six cases, the experimental tectum was allowed to remain denervated for 50 to 150 days between the time of removal of the half retinal eye and the deflection of the optic tract of the control eye to innervate the tectum. In both cases denervated for 150 days, the fish died before they could be recorded. But in the four cases denervated for 50 to 112 days, the control eye regenerated a projection similar to that of HR-60 described above. One of these, that of HR-45 denervated for 112 days, is shown in figure $7 \mathrm{C}$. The evidence for altered tectal markers was, therefore, as strong after 112 days of denervation as upon immediate innervation by the control eye.

The persistence of normal tectal markers was investigated in a similar manner. Nineteen fish (Group V-2) were operated using the procedure outlined in figure 8 . First each fish had one eye removed to denervate the contralateral tectum. Later, after 0 to 190 days, the innervated tectum was removed and the optic tract deflected ipsilaterally to induce innervation of the denervated tectum. Half of the retina of the remaining eye was also removed at the same time. The half retinal projections 
A
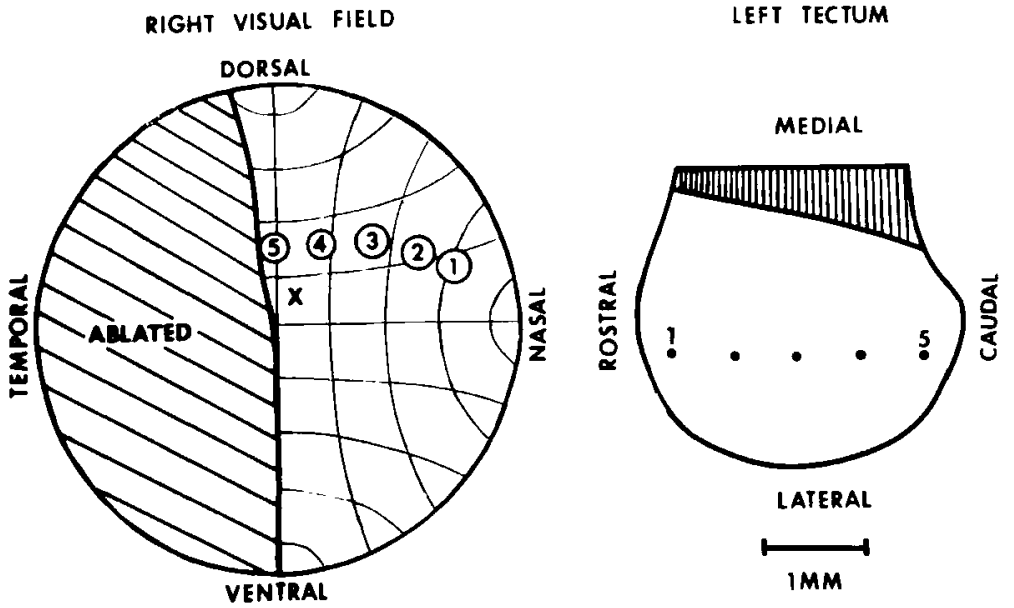

B
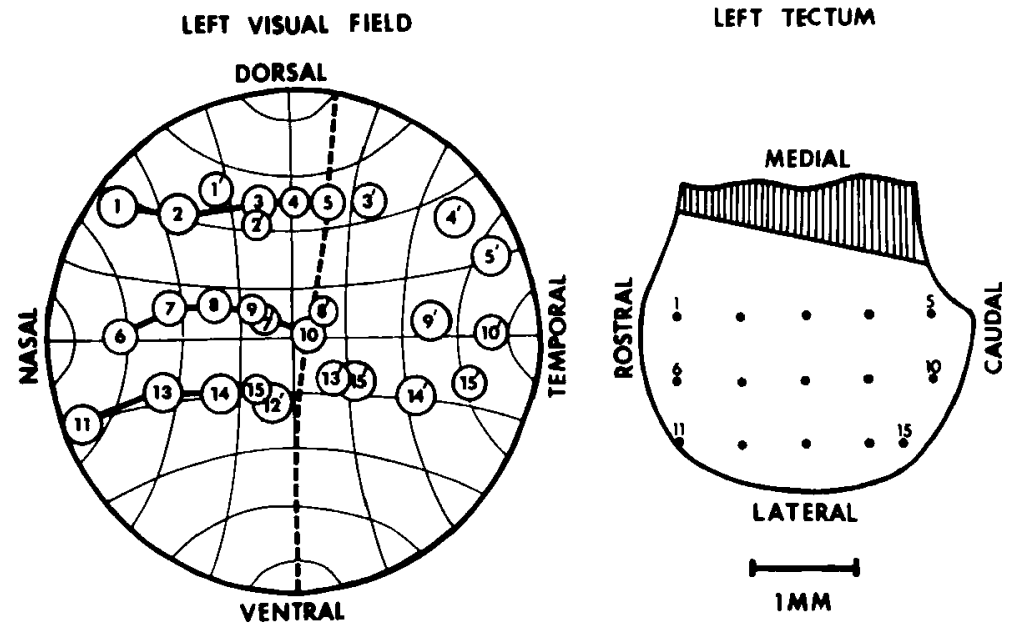

C
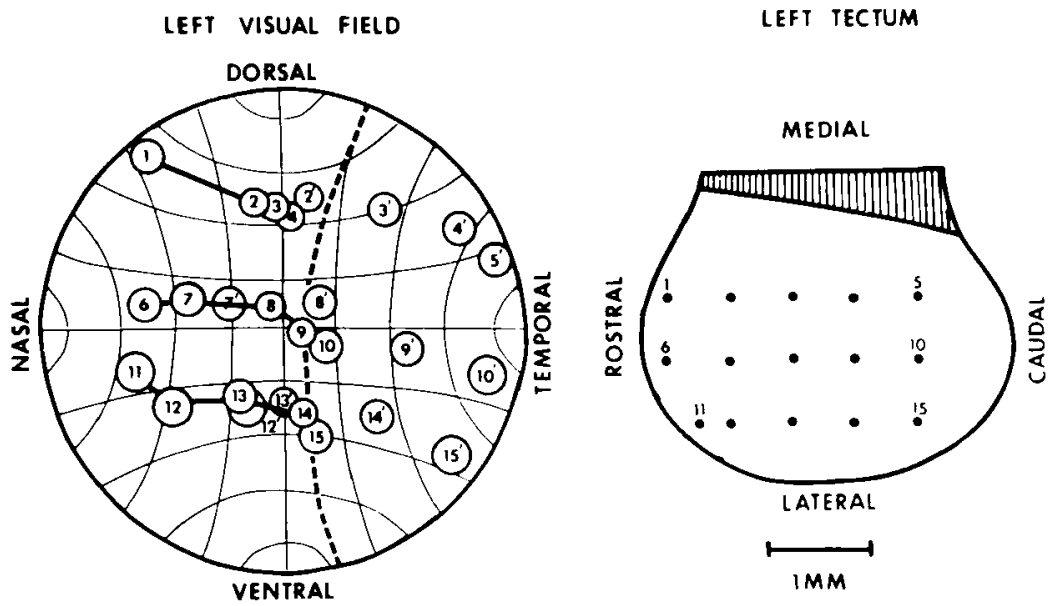

Figure 7 
formed in the denervated tectum were exam. ined both electro-physiologically and radioautographically 36 to 45 days following the deflection. Projections restricted to the appropriate half tectum would indicate persistence of tectal markers; expanded projections would indicate the absence of such markers.

Six of the fish survived the combined surgical operations and were mapped. In two control cases, the innervation took place immediately after the enucleation, and in both the projection regenerated was restricted to the appropriate rostral half tectum. One of these is shown in figure $9 \mathrm{~A}$. In the caudal half, behind the dashed line, penetrations (indicated by the squares) did not yield light driven ac tivity. This result is in agreement with the initial regeneration of the half retinal projection to the contralateral tectum (Schmidt et al., '77; Attardi and Sperry, '63), indicating that ipsilateral tectal markers are similarly followed by the fibers. Both projections were radioautographically assessed as well, and found to be restricted to the rostral half tectum in agreement with the maps. One of these is shown in figure 11B.

Of the four fish whose tecta were denervated for 60 days, only one survived and it showed a similar result (fig. 9B). The temporal half retina was removed in this case, and the fibers from the remaining nasal half regenerated selectively to the appropriate caudal tectum, bypassing open sites in the rostral area along the way.

Three of the thirteen fish with tecta denervated for 159 to 190 days survived. In contrast to the projections regenerated after short periods of denervation, all of these half retinal projections had expanded across the tecta. One of these projections, that of HR-74 (which had been denervated for 190 days prior to the deflection) is shown in figure 9C. Each line of penetrations from rostral to caudal gave an orderly, even spacing of receptive fields across the remaining half of the visual field.

The RCMF's of the unexpanded projections

Fig. 7 Innervation of the experimental tectum by the control eye alone.

A Expanded projection partially mapped in HR-60 at 209 days postoperative.

B Projection formed upon the same tectum by the control eye 42 days later.

C Projection similarly formed by the control eye on the experimental tectum in HR-45. In this case, the half retinal eye was removed 112 days before the deflection of the fibers of the control eye.

"X" marks the position of the projection of the optic disc onto the hemisphere $\left(6^{\circ}\right.$ nasal and $14^{\circ}$ dorsal to the optic axis). The dashed line (figs. 7B,C) corresponds to the edge of the ablation in the opposite half retinal eye.

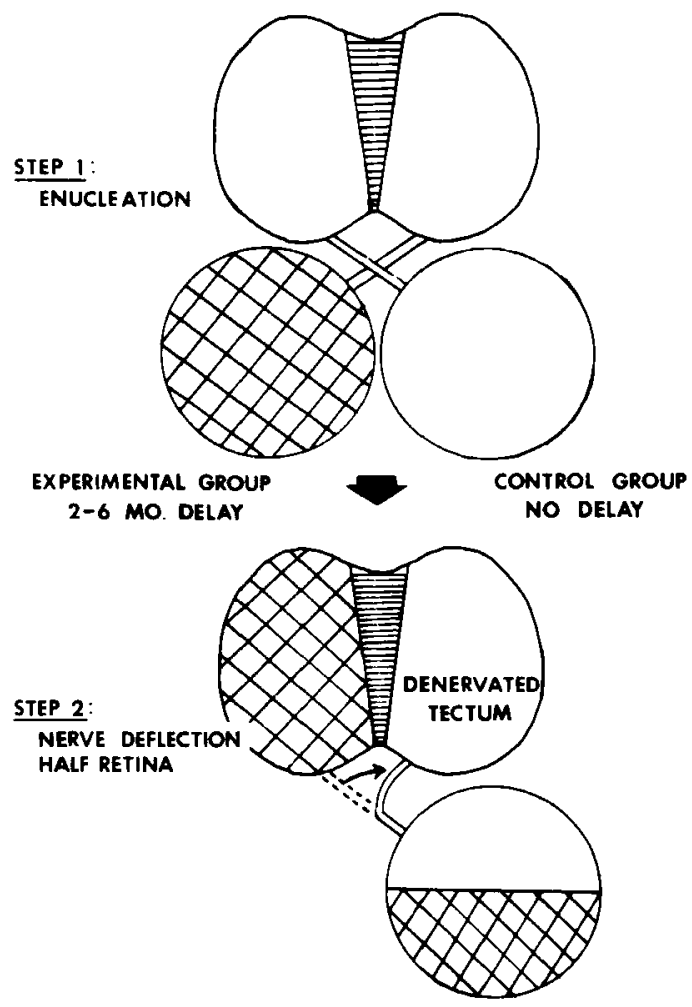

Fig. 8 Schematic diagram of the surgical procedure used in Group V-2.

were near the normal value; those of the expanded projections were over twice normal; and the MLMF's did not reflect the expansions as before. Means and standard errors for this group are also given in table 1 (Group V-2).

Penetrations in tecta which had been denervated for long periods prior to their reinnervation yielded comparatively few retinal units. This suggestion of sparse innervation was verified radioautographically in two of the fish mapped. The projection to the tectum was very light in both cases, while most of the fibers entered a large neuroma in the region of the optic tract. From this neuroma, small bundles of fibers apparently coursed over the surface of the thalamus and tectum, and also invaded the valvula of the cerebellum. Such abnormal straying of fibers was never noted in more than 20 other fish radioautographed after optic nerve deflection, and would appear to indicate a lack of attraction between the denervated tectum and the regenerating fibers.

\section{Conclusion}

Tectal markers, altered or normal, apparently persist for several months after denerva. 
A

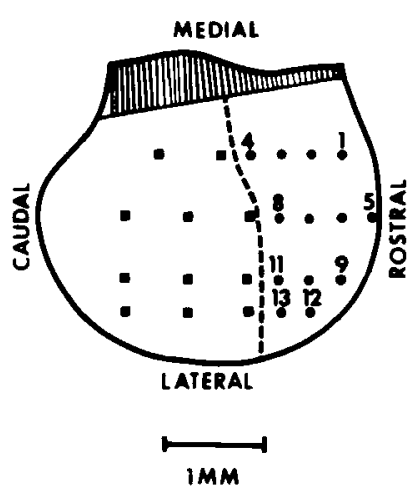

B

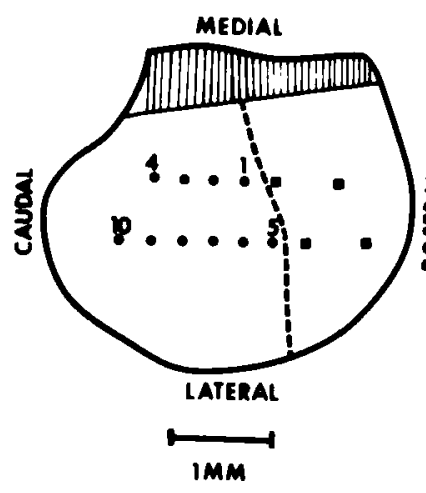

C

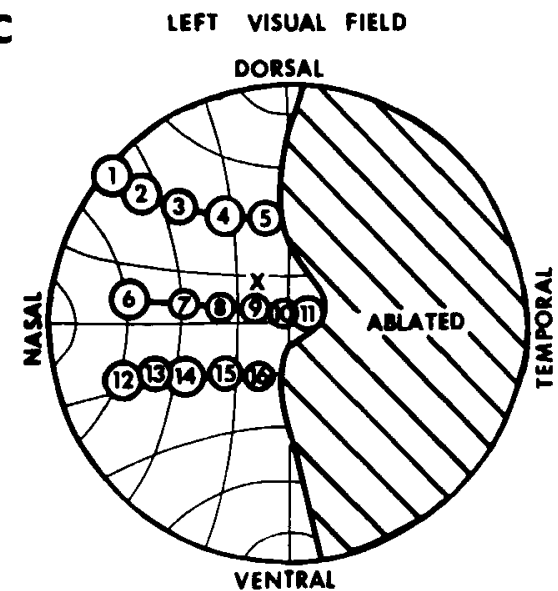

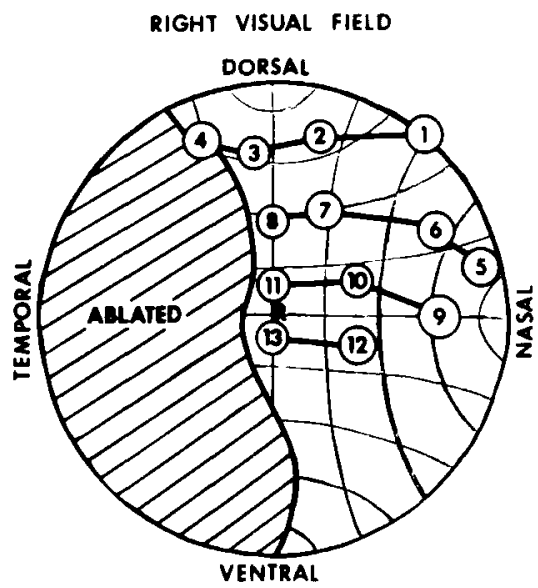

RIGHT VISUAL FIELD

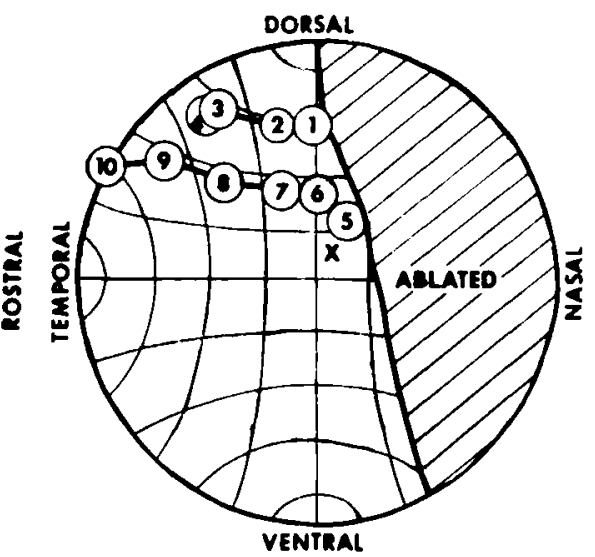

LEFT TECTUM

MEDIAL

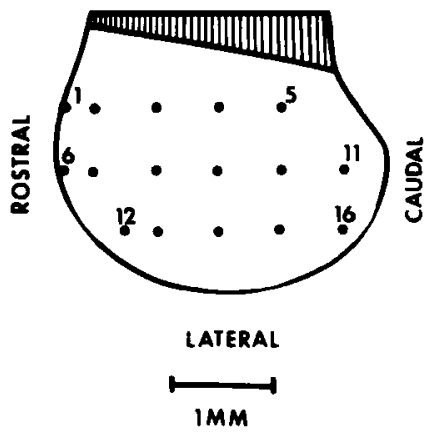

Fig 9 Half retinal projections regenerated to tecta which had been denervated for: A, 0 days; B, 60 days; and $\mathrm{C}, 190$ days before the deflection of the optic tract, and mapped 36 to 45 days later. 
tion as indicated by the formation of projections similar to the previous projections (figs. 7C, 9B). After longer periods of denervation (more than 5 months), tectal markers are no longer apparent, but innervation also occurs less readily.

\section{Effectiveness of the ipsilateral projections}

Many of the fish of Groups III-2, IV and V showed behavioral signs of reversed vision, stemming apparently from the induced ipsilateral projections (Easter and Schmidt, '77). These fish were ones in which the visual input was predominantly ipsilateral (no eye or only a half retinal eye contralateral to the remaining tectum). They circled continuously and exhibited spontaneous nystagmus, as do fish with surgically rotated eyes (Sperry, '48). The mirror symmetrically organized projections (figs. 2C, 3, 4C, 5, 7B,C, 9A,B,C), if effective, would give rise to reversed visual responses within the horizontal plane, since naso-temporal movement seen through either eye would give rise to the same sequence of activ. ity across the tectum.

This behavioral evidence for effective ipsilateral connections prompted an electrophysiological examination of the ability of the ipsilateral retinal fibers to drive those units identified as tectal cells (METHODS). In dually innervated tecta, binocular units could be found, but more unequivocal evidence of effective ipsilateral connections was found in those fish with only one eye projecting ipsilaterally (Group V). Large biphasic units, such as the one shown in figure 10 were sometimes encountered at the same depths as the retinal terminals and into the deeper levels in these 13 fish. They were identified as tectal cells from the waveform, habituation to repeated stimuli, and their continued presence as the electrode advanced past the retinal terminal bands. Occasionally the electrode could be advanced to make these units fire spontaneously at a high rate, presumably by pushing against the cell soma. Normally, as shown in figure 10, these cells fired only one or two spikes to each stimulus, always preceded at intervals of less than 5 milliseconds by the firing of a retinal fiber terminal. In the case of figure 10 , there was a dual projection similar to that shown in figures $7 \mathrm{~B}$ and $7 \mathrm{C}$, and the cell could be driven from either of the two retinal units' receptive fields separated by more than $50^{\circ}$. This would appear to indicate that retinal fibers can make effective connections within the ipsilat-

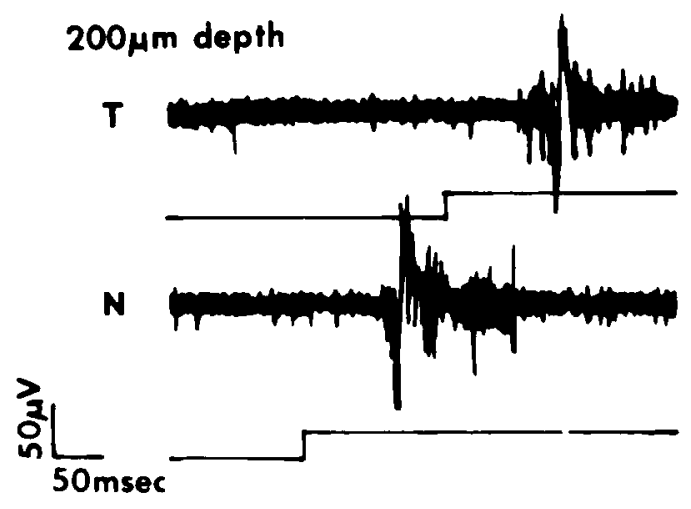

Fig. 10 Multiple unit responses recorded from a depth of $200 \mu \mathrm{m}$ (micrometer reading) in a tectum innervated only by the control ipsilateral eye (Group V-1). The retinal units recorded had two receptive fields, at nasal $(N)$ and temporal ( $\mathrm{T}$ ) positions separated by $50^{\circ}$ (for example, figs. 7B,C). Light entered the receptive fields of each retinal unit at the upward deflection of the lower trace, taken from a photocell.

eral tectum, and perhaps also at inappropriate positions in these tecta.

\section{DISCUSSION}

The results confirm Attardi and Sperry's ('63) observation of initial selective regeneration following half retinal removal, and also constitute evidence for operationally defined retinal and tectal markers (Sperry, '63). The half retina, however, does not undergo regulation as suggested by Meyer and Sperry ('73); its markers remain the same after expansion as before (Group III-1, fig. 2).

The tectal markers, however, are changed during expansion (Group IV). Altered tectal markers were strikingly demonstrated in the expanded projections formed by the control eyes (figs. 4C, 5). Innervation by the control eye alone, however, resulted in interestingly different projections (figs. 7B,C). In addition to the expanded projection from the corresponding half of the control eye, there was also a normal projection of the visual field, including the non-corresponding half, on the tectum. The presence of fibers from that half of the retina might possibly be related to a decreased competition for tectal sites during single as opposed to double innervation. The combined fibers of two corresponding half retinae (figs. $4 \mathrm{C}, 5)$ comprised a normal density of innervation; the reduced density after removal of the half retinal eye might have allowed the fibers of the other half to find sites. Zones with dual projection have also been noted during compression of the visual projection onto a half 
tectum in goldfish (Gaze and Sharma, '70; Schmidt, unpublished data), and they are consistent with the notion that tectal markers can be overridden by competition for synaptic space (Schmidt et al., '77).

Normal tectal markers also may disappear following five months denervation, as sig. nalled by the immediate regeneration of expanded half retinal projections (Group V-2, fig. $9 \mathrm{C}$ ). This period is comparable to the delay before the onset of expansion following half retinal ablation (Schmidt et al., '77). The innervation of the caudal tectum in that case was found to be very light during the early stages of expansion; likewise, the innervation of these tecta, which were denervated for comparable periods, was also very sparse. The results suggest that changes taking place in the denervated half tectum may have allowed the expansion into that area.

\section{Nature of the tectal markers}

These results point to a substantially dif. ferent role for the tectal markers than that envisaged by Sperry ('63), who postulated that they arose independently during development to be matched with those of the retina. Instead, they appear to be induced by the retinal fibers themselves, since (1) they are altered following expansion of the half retinal projection (Group IV); and (2) they apparently disappear in the absence of retinal innervation (Group V-2). There was no surgical interference with the tectum itself in either case, and therefore no possible role for regulation.

Since the regenerating fibers tended to return to the tectal positions which their counterparts had occupied in the previous projection, one possibility is that they were guided by the remnants of the previous fibers. Murray ('76), using electron microscopy to study regenerating optic fibers in the goldfish tectum, found that they travelled within glial channels, interspersed with degenerating fibers. Small amounts of this axonal debris were still present up to five months after the surgery, a period comparable to that which these operationally defined markers were found to persist (Group V). Remnants of previous retinal fibers therefore remain a possible source of the tectal markers.

Alternatively, tectal markers might consist of actual substances attached to the membranes of the tectal neurones or glial cells. As Roth (73) proposed, the retinal fibers might be able, through the action of surface glycosyl. transferases, not only to recognize, but also to alter the substances on the tectal cells which they contact, and thereby be able to change the tectal markers. Both the above possibilities are consistent with these results.

\section{Possible differences between regeneration and development}

Although the tectal markers were no longer apparent following long denervations (Group $V)$, the expanded half retinal projections regenerated to these tecta were not disorderly (fig. 9C). This suggests that tectal markers are not necessary for topographic ordering of retinal fibers. Indeed, regenerating retinal fibers generally maintain topographic order all along the pathway before reaching the tectum (Attardi and Sperry, '63; Horder, '74). This independent sorting out of retinal fibers makes it conceivable that tectal markers are initially imposed on the tectum by the retinal fibers. No such tectal markers, dependent upon a previous projection could have been present during development.

Recent studies designed to test for polarization of the tectum during development gave results consistent with this notion. Chung and Cooke ('75) rotated the embryonic tectal region of the neural tube in Xenopus before the arrival of optic fibers, and found no inversion of the resulting retinal projection. The tectum apparently does not have either markers or polarity prior to its innervation by optic fibers, whereas after their arrival, rotations of portions of the tectum in either premetamorphic (Jacobson, personal communication) or postmetamorphic Xenopus (Levine and Jacobson, 74) resulted in locally rotated projections. In Xenopus at least, the acquisition of tectal polarity (and possibly also markers) is correlated with the initial ingrowth of optic fibers. In adult goldfish, these results show a corresponding dependence of the tectal markers on the previous projection to the tectum.

\section{ACKNOWLEDGMENTS}

I thank Doctors S. S. Easter, P. R. Johns, M. K. Powers, S-H. Chung, R. M. Gaze and J. Cooke for useful comments and discussion. This work was supported by P. H. S. Grants EY-00168 (to S. S. E.) and GM-1355.

\section{LITERATURE CITED}

Attardi, D. G., and R. W. Sperry 1963 Preferential selection of central pathways by regenerating optic fibers. Exp. Neurol., 7: 46-64.

Chung, S-H., and J. E. Cooke 1975 Polarity of structure and 
of ordered nerve connections in the developing amphibian brain. Nature, 258: 126-132.

Easter, S. S., and J. T. Schmidt 1977 Reversed visuomotor behaviour mediated by induced ipsilateral retinal projections in goldfish. J. Neurophysiol., in press.

Easter, S. S., J. T. Schmidt and S. M. Leber (1977, in preparation) The paths and destinations of the induced ipsilateral retinal projection in goldfish.

Gaze, R. M., and M. J. Keating 1972 The visual system and "Neuronal Specificity". Nature, 237: 375-378.

Gaze, R. M., and S. C. Sharma 1970 Axial differences in the reinnervation of the goldfish optic tectum by regenerating optic nerve fibres. Exp. Brain Res., 10: 171-181.

Horder, T. J. 1974 Evidence that afferent optic nerve fibres regenerate selectively through specific routes into the tectum. J. Physiol., 241: 84P (Abstract).

Jacobson, M. 1968 Development of neuronal specificity in retinal ganglion cells of Xenopus. Develop. Biol., 17 202-218.

Jacobson, M, and R. M. Gaze 1965 Selection of appropriate tectal connections by regenerating optic nerve fibers in adult goldfish. Exp. Neurol., 13: 418-430.

Jacobson, M., and R. L. Levine 1975 Discontinuous mapping of retina on to tectum innervated by both eyes. Brain Res., 98: 172.176.

Levine, R. L., and M. Jacobson 1974 Deployment of optic nerve fibers is determined by positional markers in the frog's tectum. Exp. Neurol., 43: 527-538.

Matthey, R. 1925 Recuperation de la vue aprés résection des nerfs optiques, chez le Triton adulte. Compt. rend. Soc. Biol., 94: 4-5.

Meyer, R. L., and R. W. Sperry 1973 Tests for neuroplasticity in the anuran retino-tectal system. Exp. Neurol., 40: 525-539.

Murray, M. 1976 Regeneration of retinal axons into the goldfish optic tectum. J. Comp. Neur., 168: 175-195.
O'Benar, J. D. 1971 Electrophysiology of Goldfish Optic Tectum. Ph.D. thesis, University of Illinois.

Roth, S. 1973 A molecular model for cell interactions. Quart. Rev. Biol., 48: 541-563.

Schmidt, J. T., C. M. Cicerone and S. S. Easter 1974 Reorga nization of the retino-tectal projection in goldfish. Abstract Soc. Neurosci., p. 610.

1977 Expansion of the half retinal projection to the tectum in goldfish: An electrophysiological and anatomical study. J. Comp. Neur., 177: 257.278.

Sharma, S. C. 1972 Redistribution of visual projections in altered optic tecta of adult goldfish. P.N.A.S. (U.S.A.), 69: $2637-2639$

1973 Anomalous retinal projection after removal of contralateral optic tectum in aduit goldfish. Exp. Neu. rol., 41: $661-669$.

Sperry, R. W. 1944 Optic nerve regeneration with return of vision in anurans. J. Neurophysiol., 7: 57-69.

1945 Restoration of vision after uncrossing the optic nerves and after contralateral transposition of the eye. J. Neurophysiol., $8: 15-28$.

1948 Patterning of central synapses in regeneration of the optic nerve in teleosts. Physiol. Zool., 21: $351 \cdot 361$.

1963 Chemoaffinity in the orderly growth of nerve fiber patterns and connections. P.N.A.S. (U.S.A.), 50: 703-709

Szekely, G. 1954 Zur ausbildung der lokalen funktionellen Spezifitat der Retina. Acta Biol. Acad. Sci. Hung., 5: 156-167.

Yoon, M. G. 1971 Reorganization of the retino-tectal projection following surgical operations on the optic tectum in goldfish. Exp. Neurol., 33: 395-411.

1972 Synaptic plasticities of retina and tectum in goldfish. Amer. Zoöl., 12: 106 (Abstract). 


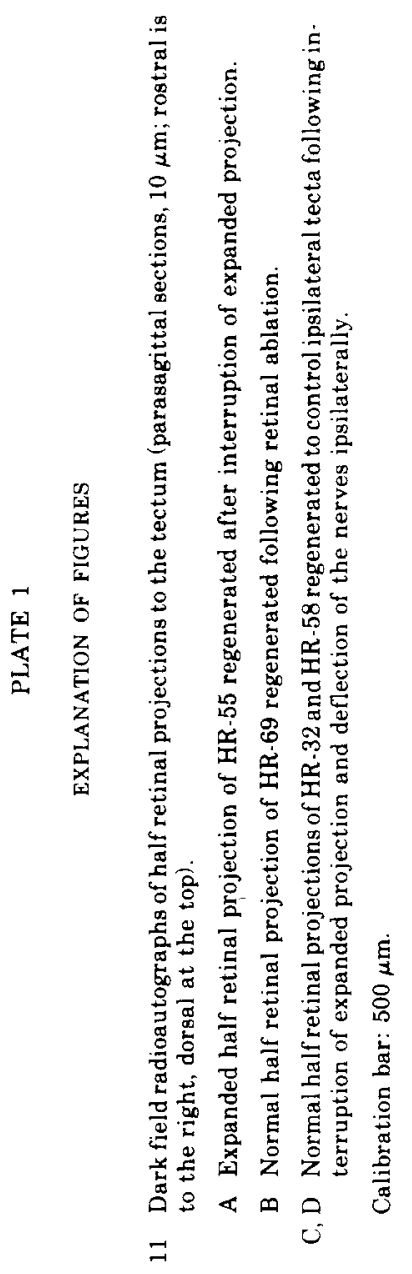




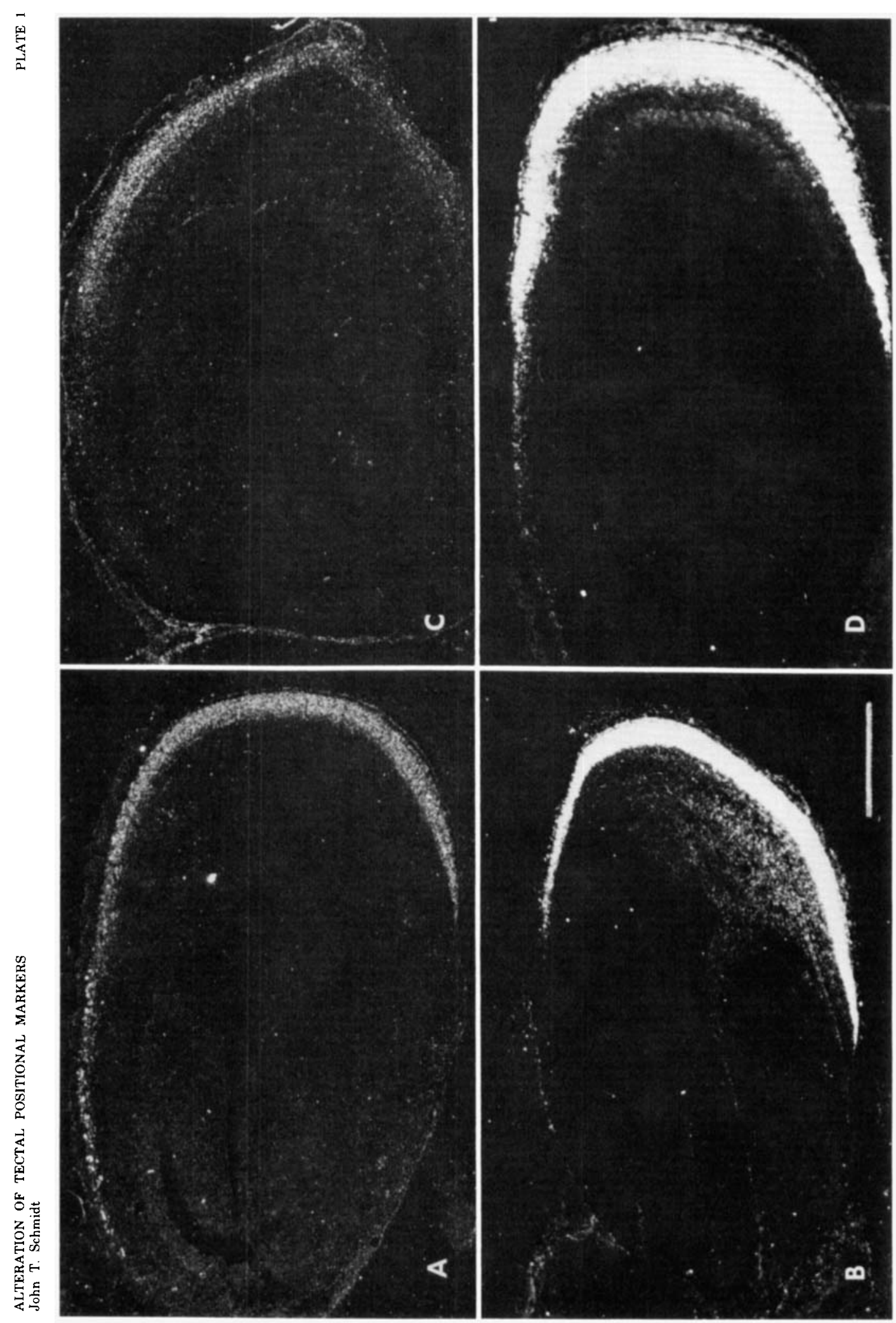


PLATE 2

EXPLANATION OF FIGURES

12 Dark field radioautographs of ipsilateral projections from intact eyes (parasagitta] plane, $10 \mu \mathrm{m}$, rostral is to the right, dorsal at the top).

A Projection of control eye regenerated to the tectum containing the expanded half retinal projection in HR.34.

B Long term projection ( 394 days) of intact eye to ipsilateral tectum containing unexpanded half retinal projection.

Calibration bar: $500 \mu \mathrm{m}$. 

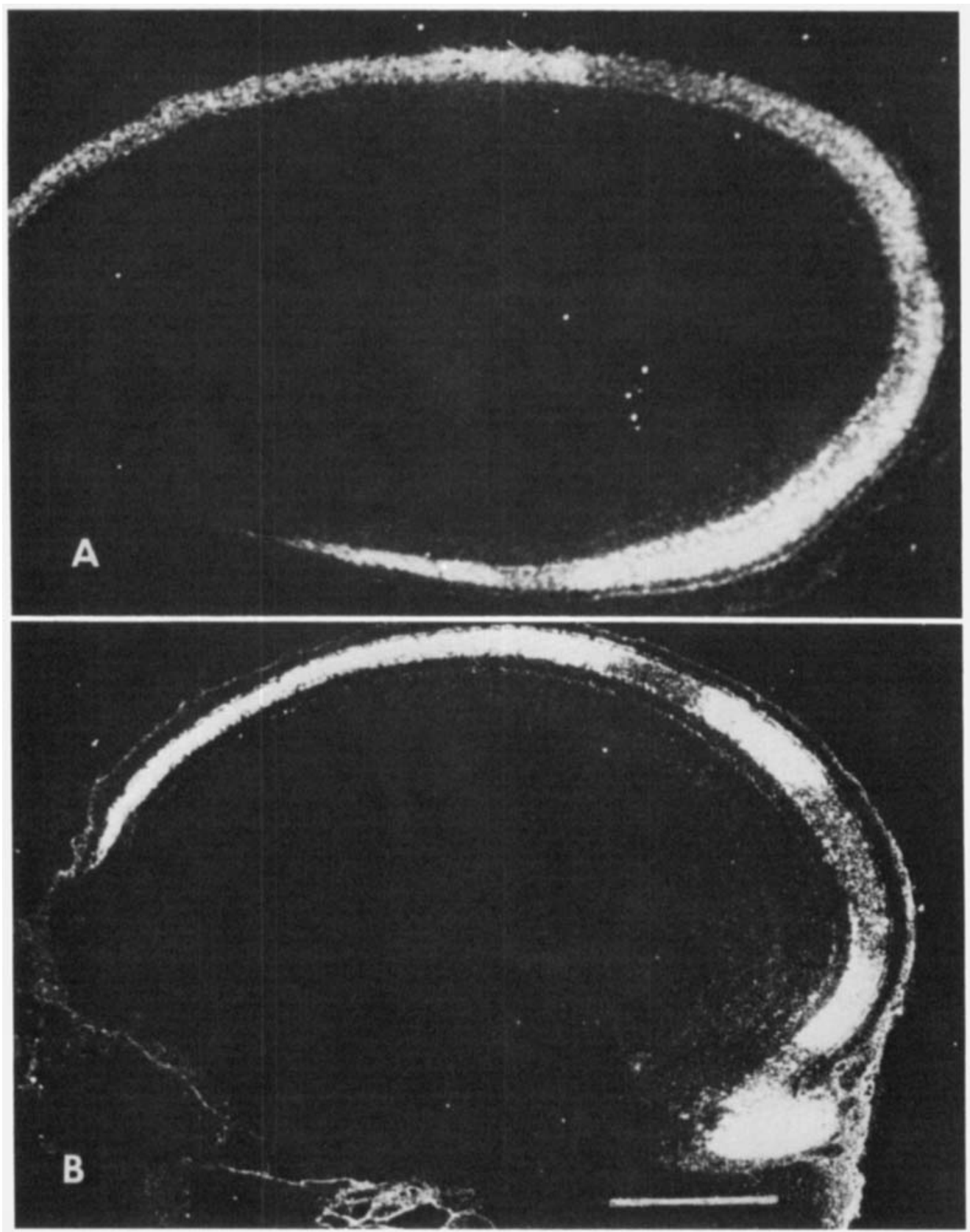